\title{
Comparison of Postoperative Opioid Use in Mothers with Neonates in the Neonatal Intensive Care Versus in the Regular Nursery or Rooming In
}

\author{
Sepideh Mehri*, Lauren Ruggiero and Iffath A Hoskins \\ Department of OBGYN, NYU School of Medicine, New York, NY, USA \\ ${ }^{\star}$ Corresponding author: Sepideh Mehri, Department of OBGYN, NYU School of Medicine, 550 First Avenue, Rm NB 9N1, New York, NY, USA
}

Received: August 27, 2021; Accepted: September 06, 2021; Published: September 09, 2021

\begin{abstract}
Objective: To evaluate if post cesarean section opioid usage is greater for mothers with neonates in the Neonatal Intensive Care Unit (NICU) versus in mothers with neonates in the well born nursery who were encouraged to "room in" with their mothers (WBN).

Methods: This was a retrospective chart review that analyzed 8136 records of women delivering at an urban academic institution. The study period was from January 1, 2013, through December 12, 2018. Daily post-operative opioid usage was assessed. Chi-square analysis was used to evaluate for differences between the groups.
\end{abstract}

Conclusions: Post-operative mothers with neonates in the NICU did not have greater opioid usage versus those with neonates in the WBN. However, post cesarean section mothers with neonates who required major surgery for life threatening diagnoses had significantly greater opioid usage.

Clinical Trial Registration: “Opioid use by Postpartum Mothers" (s19-01134).

Keywords: Opioid, Postpartum, Neonates, NICU

\section{Introduction}

The prevalence of opioid abuse disorder has markedly increased over the past years, having doubled in occurrence between 1988 to 2011 [11]. It has now become a national emergency [2,20] leading to multiple organizations and institutions focusing on with how to prevent, diagnose and treat this crisis $[12,20]$.

Post-operative opioid use presents pain management dilemmas for mothers as it affects their ability to be alert and engaged in order to nurture their newborns. Mothers with neonates in the NICU may have additional stresses and thus desire "round the clock" pain management as opposed to "as needed" as a means to avoid the distractor of postpartum pain.

Although other areas of opioid use have been extensively studied including those at greater risk for substance abuse $[1,2,4,7,8,10,11,14,20,30]$ and provider prescription patterns [14$16,19,22]$, no research to date has focused on whether there is a difference in postoperative opioid use in women with neonates in the NICU versus the WBN.

The aim of our study is to determine whether neonatal NICU admission poses an additional stressor for post-operative mothers and results in increased use of opioids during this vulnerable period.

\section{Methods}

After receiving IRB approval, a retrospective chart review of 8136 women who delivered at an urban academic institution from January 2013-December 2018 was performed. Information regarding daily post-operative opioid use as well as the location of the neonate (NICU versus WBN) was collected. Post-operative opioid usage for mothers with neonates in WBN (Group A) was compared to usage in mothers with neonates in the NICU (Group B). Opioid usage was stratified into 24-hour blocks. Substance abusers and chronic opioid users were excluded.

A subgroup analysis was performed for the indication of the NICU admission. Chi-square was used to analyze the data.

\section{Results}

All post-operative patients ( $\mathrm{n}=8136$, comprised of 6509 patients in group A [WBN] and 1627 patients in group B [NICU]) were prescribed both opioids and non-narcotic analgesics. Both agents were used by $84 \%$ of mothers while $16 \%$ used only non-narcotic analgesics. No patients exclusively used opioids alone.

During each 24 hour block, there were no statistically significant differences in opioid usage between the mothers with babies in the NICU versus the WBN (43\% vs $45 \%$, Post-Operative Day (POD) 1, $81 \%$ vs $80 \%$, POD2, $72 \%$ vs $70 \%$, POD $3,20 \%$ vs $23 \%$, POD 4 ) (Table 1 ). 
The most common indications for NICU admissions included prematurity (12\%), sepsis (4\%), and neonates requiring major surgery for life threatening anomalies (3\%) while other diagnoses included hypoglycemia, transient tachypnea of newborn, meconium aspiration and observation for other benign conditions represented smaller proportions (Table 2).

Mothers of NICU neonates (Group B) with life-threatening anomalies and who required corrective surgery (Group B1) had increased opioid usage on POD 1 and 4 when compared to those in Group A; this trend was also seen when compared to mothers whose babies were in the NICU but who did not have life threatening conditions on POD 1-4. (Group B2) (Tables 3 and 4).

Table 1: Opioid usage between Groups A and B

\begin{tabular}{|l|c|c|c|}
\hline Hospital days & Group A $(\mathbf{n}=\mathbf{6 5 0 9})$ & Group B $(\mathbf{n}=\mathbf{1 6 2 7})$ & P-value \\
\hline POD1 & $43 \%(\mathrm{n}=2799)$ & $45 \%(\mathrm{n}=732)$ & 0.184 \\
\hline POD2 & $81 \%(\mathrm{n}=5272)$ & $80 \%(\mathrm{n}=1302)$ & 0.144 \\
\hline POD3 & $72 \%(\mathrm{n}=4686)$ & $70 \%(\mathrm{n}=1139)$ & 0.112 \\
\hline POD4 & $20 \%(\mathrm{n}=1302)$ & $23 \%(\mathrm{n}=372)$ & 0.142 \\
\hline
\end{tabular}

Group A: mothers with neonates in the regular nursery.

Group B: Mothers of infants in NICU.

Table 2: Indications for admission and Opioid usage in Group B.

\begin{tabular}{|c|c|c|c|c|}
\hline & POD1 & POD2 & POD3 & POD4 \\
\hline Prematurity & \multirow{2}{*}{$39 \%(n=76)$} & \multirow{2}{*}{$79 \%(\mathrm{n}=154)$} & \multirow{2}{*}{$65 \%(n=127)$} & \multirow{2}{*}{$19 \%(n=37)$} \\
\hline $12 \%(n=195)$ & & & & \\
\hline Sepsis & \multirow{2}{*}{$41 \%(n=27)$} & \multirow{2}{*}{$74 \%(\mathrm{n}=48)$} & \multirow{2}{*}{$67 \%(n=44)$} & \multirow{2}{*}{$22 \%(\mathrm{n}=14)$} \\
\hline $4 \%(n=65)$ & & & & \\
\hline Serious problems & \multirow{2}{*}{$58 \%(\mathrm{n}=28)$} & \multirow{2}{*}{$89 \%(n=44)$} & \multirow{2}{*}{$81 \%(\mathrm{n}=40)$} & \multirow{2}{*}{$32 \%(n=16)$} \\
\hline $3 \%(n=49)$ & & & & \\
\hline Other & \multirow[b]{2}{*}{$43 \%(567)$} & \multirow{2}{*}{$78 \%(\mathrm{n}=1028)$} & \multirow{2}{*}{$68 \%(n=896)$} & \multirow[b]{2}{*}{$21 \%(n=277)$} \\
\hline $81 \%(n=1318)$ & & & & \\
\hline
\end{tabular}

Other: Hypoglycemia, meconium aspiration, mild respiratory distress, r/o infection

Table 3: Opioid usage between Groups A and B1.

\begin{tabular}{|l|c|c|c|}
\hline Hospital days & Group A $(\mathbf{n}=\mathbf{6 5 0 9})$ & Group B1 $(\mathbf{n}=49)$ & P-value \\
\hline POD1 & $43 \%(\mathrm{n}=2799)$ & $58 \%(\mathrm{n}=21)$ & 0.004 \\
\hline POD2 & $81 \%(\mathrm{n}=5272)$ & $89 \%(\mathrm{n}=44)$ & 0.113 \\
\hline POD3 & $72 \%(\mathrm{n}=4686)$ & $81 \%(\mathrm{n}=40)$ & 0.134 \\
\hline POD4 & $20 \%(\mathrm{n}=1302)$ & $32 \%(\mathrm{n}=16)$ & 0.027 \\
\hline
\end{tabular}

Group A: mothers with neonates in Well Born Nursery. Group B1: Mothers of Infants with Serious problems.

Table 4: Opioid usage between Groups B1 and B2.

\begin{tabular}{|l|c|c|c|}
\hline Hospital days & Group B1 (n=49) & Group B2 $(\mathbf{n}=195)$ & P-value \\
\hline POD1 & $58 \%(n=21)$ & $39 \%(n=76)$ & 0.0215 \\
\hline POD2 & $89 \%(n=44)$ & $79 \%(n=154)$ & 0.0833 \\
\hline POD3 & $81 \%(n=40)$ & $65 \%(n=127)$ & 0.026 \\
\hline POD4 & $32 \%(n=16)$ & $19 \%(n=37)$ & 0.0379 \\
\hline
\end{tabular}

Group B1: Mothers of Infants with Serious problems.

Group B2: Mothers of infant's prematurity.
At the time of discharge, all mothers received a prescription for narcotics, regardless of their choice of analgesics during the hospitalization, i.e. combinations of narcotics and non-narcotics, or only non-narcotics.

\section{Discussion}

Opioid use often starts with the treatment of acute pain $[6,10,12]$ and it has been well documented that a single exposure can lead to persistent dependence [19]. For many women, their first exposure to opioids follows childbirth. Approximately 1 in 10 women suffer severe postpartum pain within the first 36 hours after delivery. Opioids are generally the mainstay of treatment at this time [14]. Multiple studies have documented inpatient use of opioids rates up to $58 \%$ for vaginal deliveries and $100 \%$ for cesarean sections [22] with $24 \%$ of patients continuing to use opioids even in the last 24 hours of hospitalization [2].

As many patients' first exposure to opioids likely occurs during the post-operative period, our study sought to better understand opioid use in mothers who would be expected to undergo additional stresses due to their neonates being separated from their babies while admitted to the NICU. Interestingly, we did not find that these mothers had increased post-operative narcotic usage unless they were in the small subgroup of women whose babies were undergoing surgery for life threatening conditions.

Strengths of our study included the large sample size from a single academic institution with an existing standardized postpartum order set. Limitations of our study include lack of analysis of opioid use for women whose babies were briefly in the NICU but were transferred to the well-baby nursery or roomed in prior to mother's discharge as well as an overall small sample size of mothers with neonates with "life threating" issues.

\section{Conclusion}

To our knowledge, this is the first study focusing on comparison of opioid use in mothers with neonates in the NICU versus in the newborn nursery or rooming in. This study illustrates that despite the perceived greater stresses of being separated from their neonates, only those mothers whose neonates had severe life-threatening conditions needing corrective surgery used more opioids on a "round the clock" basis. Given the findings that all patients received a narcotic prescription at discharge, even though $16 \%$ had never used a narcotic during the hospitalization, further attention should be paid towards avoiding arbitrary prescribing narcotics in these circumstances. These findings should inform post-operative pain management plans in that mother whose babies are in the NICU may not require additional narcotics unless the neonates are undergoing corrective surgery for life threatening conditions. In addition, if mothers of neonates admitted to the NICU have not utilized narcotic prescriptions during the post-operative period they should not receive such prescriptions at discharge, as this will help to avoid the occurrence of chronic substance abuse. 


\section{References}

1. Ailes EC, Dawson AL, Lind JN, Gilboa SM, Frey MT, et al. (2015) Centers for Disease Control and Prevention (CDC). Opioid prescription claims among women of reproductive age--United States, 2008-2012. MMWR Morb Mortal Wkly Rep 64: 37-41. [crossref]

2. Badreldin N, Grobman WA, Yee LM (2018) Inpatient opioid use after vaginal delivery. Am J Obstet Gynecol 219: 608.e1-608.e7. [crossref]

3. Baker DW (2017) History of the Joint Commission's Pain Standards: Lessons for Today's Prescription Opioid Epidemic. JAMA 317: 1117-1118. [crossref]

4. Bateman BT, Franklin JM, Bykov K, Avorn J, Shrank WH, et al. (2016) Persistent opioid use following cesarean delivery: patterns and predictors among opioid-naïve women. Am J Obstet Gynecol 215: 353.e1-353.e18. [crossref]

5. Becker NV, Gibbins KJ, Perrone J, Maughan BC (2018) Geographic variation in postpartum prescription opioid use: Opportunities to improve maternal safety. Drug Alcohol Depend 188: 288-294. [crossref]

6. Carvalho B, Butwick AJ (2017) Postcesarean delivery analgesia. Best Pract Res Clin Anaesthesiol 31: 69-79. [crossref]

7. Centers for Disease Control and Prevention (CDC) (2010) Adult use of prescription opioid pain medications - Utah, 2008. MMWR Morb Mortal Wkly Rep 59: 153-157. [crossref]

8. Deyo RA, Hallvik SE, Hildebran C, Marino M, Dexter E, et al. (2017) Association Between Initial Opioid Prescribing Patterns and Subsequent Long-Term Use Among Opioid-Naïve Patients: A Statewide Retrospective Cohort Study. J Gen Intern Med 32: 21-27. [crossref]

9. Ko JY, Tong VT, Haight SC, Terplan M, Snead C, et al. (2020) Obstetriciangynecologists' practice patterns related to opioid use during pregnancy and postpartum-United States, 2017. J Perinatol 40: 412-421. [crossref]

10. Komatsu R, Ando K, Flood PD (2020) Factors associated with persistent pain after childbirth: a narrative review. Br J Anaesth 124: e117-e130. [crossref]

11. Maeda A, Bateman BT, Clancy CR, Creanga AA, Leffert LR (2014) Opioid abuse and dependence during pregnancy: temporal trends and obstetrical outcomes. Anesthesiology 121: 1158-1165. [crossref]
12. Mills JR, Huizinga MM, Robinson SB, Lamprecht L, Handler A, et al. (2019) Draft Opioid-Prescribing Guidelines for Uncomplicated Normal Spontaneous Vaginal Birth. Obstet Gynecol 133: 81-90. [crossref]

13. Nørgaard M, Nielsson MS, Heide-Jørgensen U (2015) Birth and Neonatal Outcomes Following Opioid Use in Pregnancy: A Danish Population-Based Study. Subst Abuse 9: 5-11. [crossref]

14. Osmundson SS, Min JY, Grijalva CG (2019) Opioid prescribing after childbirth: overprescribing and chronic use. Curr Opin Obstet Gynecol 31: 83-89. [crossref]

15. Osmundson SS, Raymond BL, Kook BT, Lam L, Thompson EB, et al. (2018) Individualized Compared With Standard Postdischarge Oxycodone Prescribing After Cesarean Birth: A Randomized Controlled Trial. Obstet Gynecol 132: 624-630. [crossref]

16. Osmundson SS, Wiese AD, Min JY, Hawley RE, Patrick SW, et al. (2019) Delivery type, opioid prescribing, and the risk of persistent opioid use after delivery. Am J Obstet Gynecol 220: 405-407. [crossref]

17. Patrick SW, Schumacher RE, Benneyworth BD, Krans EE, McAllister JM, et al. (2012) Neonatal abstinence syndrome and associated health care expenditures: United States, 2000-2009. JAMA 307: 1934-1940. [crossref]

18. Porter J, Jick H (1980) Addiction rare in patients treated with narcotics. N Engl J Med 302: 123. [crossref]

19. Rogers RG, Nix M, Chipman Z, Breen M, Dieterichs C, et al. (2019) Decreasing Opioid Use Postpartum: A Quality Improvement Initiative. Obstet Gynecol 134: 932940. [crossref]

20. Shah A, Hayes CJ, Martin BC (2017) Characteristics of Initial Prescription Episodes and Likelihood of Long-Term Opioid Use - United States, 2006-2015. MMWR Morb Mortal Wkly Rep 66: 265-269. [crossref]

21. Tobon AL, Habecker E, Forray A (2019) Opioid Use in Pregnancy. Curr Psychiatry Rep 21: 118. [crossref]

22. Sanchez Traun KB, Schauberger CW, Ramirez LD, Jones CW, Lindberg AF, et al (2019) Opioid prescribing trends in postpartum women: a multicenter study. Am J Obstet Gynecol MFM 1: 100055. [crossref]

\section{Citation:}

Mehri S, Ruggiero L, Hoskins IA (2021) Comparison of Postoperative Opioid Use in Mothers with Neonates in the Neonatal Intensive Care Versus in the Regular Nursery or Rooming In.. Integr Gyn Obstet J Volume 4(3): 1-3. 